Lenz Alberto Alves Cabral ${ }^{a}$ (iD https://orcid.org/0000-0002-1401-234X

Zaida Aurora Sperli Geraldes Soler (iD) https://orcid.org/0000-0001-8978-4400

Anneliese Domingues Wysocki

(iD) https://orcid.org/0000-0002-8381-9999

a Faculdade de Medicina de São José do Rio Preto. São José do Rio Preto, $\mathrm{SP}$, Brasil.

${ }^{b}$ Universidade Federal de Mato Grosso do Sul. Três Lagoas, MS, Brasil.

Contato:

Lenz Alberto Alves Cabral

E-mail:

lenzcabral@yahoo.com.br

Trabalho com base na dissertação de mestrado de Lenz Alberto Alves Cabral, intitulada Nexo causal no acidente de trabalho, pelo Programa de Pós-Graduação em Enfermagem da Faculdade de Medicina de São José do Rio Preto (Famerp).

Os autores declaram que o trabalho não foi subvencionado e que não há conflitos de interesses.

\section{Pluralidade do nexo causal em acidente de trabalho/ doença ocupacional: estudo de base legal no Brasil}

\author{
Plurality of the causal nexus in occupational \\ accidents/diseases: a legal basis study in Brazil
}

\section{Resumo}

Introdução: a determinação do nexo causal do acidente de trabalho/doença ocupacional é de suma importância, pois sua análise envolve fatores ideológicos, éticos, humanísticos e legais, sendo realizada nos âmbitos trabalhista, previdenciário e cível. Objetivo: identificar e sistematizar atos normativos legais para subsidiar a compreensão interpretativa do nexo causal entre o sinistro laboral e o trabalho, nos âmbitos trabalhista, previdenciário e cível. Métodos: ensaio crítico-reflexivo, com base em levantamento e sistematização da legislação trabalhista brasileira que dá suporte ao estabelecimento do nexo causal no acidente do trabalho pelos atores sociais legalmente responsáveis por sua determinação. Resultados: são identificadas três modalidades de nexo causal: trabalhista, pelos Serviços Especializados de Engenharia de Segurança e Medicina do Trabalho (SESMT); previdenciário, pelo Instituto Nacional do Seguro Social (INSS); e cível, pela Justiça do Trabalho. A Lei nº 8.213/1991 é referência comum para as três instituições; outros atos legais normativos são específicos no âmbito de cada instituição: as Normas Regulamentadoras do Trabalho (SESMT); a Instrução Normativa 31 (INSS) e o Código Civil (Justiça do Trabalho). Conclusão: o uso correto da legislação facilita o estabelecimento do elo entre o acidente e o trabalho, auxiliando na sua compreensão, padronização, diminuição de conflitos e aumento da notificação.

Palavras-chave: acidentes de trabalho; saúde do trabalhador; legislação trabalhista.

\begin{abstract}
Introduction: determining the causal nexus of occupational accidents/diseases is very important, because its analysis involves ideological, ethical, humanistic, and legal factors, and it takes place in the occupational, social security, and civil law spheres. Objective: to identify and systematize normative legal acts to support the interpretive understanding of the causal nexus between occupational accidents and work, in the occupational, social security, and civil law spheres. Methods: critical-reflective essay, based on gathering and systematization of the Brazilian labor law that gives support to the establishment of the occupational accidents causal nexus by the social actors who are legally responsible for its determination. Results: three types of legal causal nexus were identified: job-related, by the Specialized Services in Safety Engineering and Occupational Medicine (SESMT); social security, by the National Institute of Social Security (INSS); and civil law, by the Labor Court. Law No. 8,213/1991 is the common reference for the three mentioned institutions; other normative legal acts are specific within each institution: the Occupational Regulatory Standards (SESMT); the Normative Instruction 31 (INSS), and the Civil Code (Labor Court). Conclusion: the correct use of the law may help to establish the relationship between accident and work, assisting in its understanding, standardization, in reducing conflicts and increasing notifications.
\end{abstract}

Keywords: occupational accidents; occupational health; labor legislation. 


\section{Introdução}

O acidente de trabalho e a doença ocupacional representam um sério problema de saúde pública e para a economia de uma nação ${ }^{1}$. No Brasil, sua análise previdenciária está contemplada principalmente na Lei de Benefícios da Previdência Social $\mathrm{n}^{\circ}$ 8.213, de 24 de julho de $1991^{2}$, e Lei Complementar no 150 , de $1^{\circ}$ de junho de $2015^{3}$.

A análise do nexo ou liame causal no acidente de trabalho envolve na sua determinação uma série de fatores de ordem ideológica, ética, legal e humanística e três elementos são essenciais: 1) o diagnóstico do agravo à saúde, doença, ou sequela com dano físico ou mental; 2) a presença no ambiente de trabalho de riscos ocupacionais capazes de causar o agravo à saúde; e 3) o estabelecimento da relação entre o agravo apresentado e o ambiente de trabalho, ou seja, o nexo causal ${ }^{4}$.

Embora se fale genericamente em nexo de causalidade com o trabalho, ao se analisar a relação de um acidente ou doença laboral com o trabalho, devem ser considerados diferentes e sucessivos nexos parciais ${ }^{5}$ :

I - Nexo entre a "atividade e a exposição ao risco": exige que se demonstre que determinada atividade expõe o operador a determinado risco;

II - Nexo entre o risco e a lesão: deve-se demonstrar que determinado risco causa determinada lesão;

III - Nexo causal entre a lesão e a alteração funcional: deve ser analisada a compatibilidade entre a lesão e a alteração funcional (quando a lesão causa alteração funcional específica).

Tendo por referência a legislação brasileira, o nexo entre o sinistro laboral e o trabalho deve ser estabelecido com base no artigo 19 da Lei 8.213/1991, atendendo primeiramente a três critérios: subordinação (serviço efetivo pelo exercício do trabalho a serviço da empresa), dano (lesão ou distúrbio) e incapacidade funcional ${ }^{5}$.

Nesse contexto, ainda precisam ser consideradas as situações/ocorrências de equiparação e aquelas que são descartadas como acidente do trabalho. Ao se constatar a doença ocupacional, o estabelecimento do nexo com o trabalho envolve, além disso, o conhecimento técnico da patologia em questão, a identificação do respectivo risco laboral e a possibilidade da exposição ao risco de produzir tal patologia. Assim, pressupõe-se uma sustentação técnico-científica de ambos, patologia e risco, amalgamados entre si pela legislação brasileira, resultando na união indissolúvel técnico-legal, representada pelo nexo causal ${ }^{6}$.
Na análise da causalidade no acidente de trabalho é possível identificar especificidades na determinação de nexos causais conforme a instituição que o determina, da seguinte forma: nexo trabalhista, estabelecido pelos Serviços Especializados em Engenharia de Segurança e em Medicina do Trabalho (SESMT); nexo previdenciário, determinado pelo Instituto Nacional do Seguro Social (INSS); nexo cível, realizado pela Justiça do Trabalho ${ }^{6,7}$.

O nexo trabalhista é de natureza qualitativa, pois resulta do registro ou o não da Comunicação de Acidente de Trabalho (CAT) ao INSS, sendo uma atribuição do SESMT ${ }^{8}$.

O nexo previdenciário, também de natureza qualitativa, pode ser positivo ou negativo, dependendo da homologação da CAT, sendo de atribuição exclusiva da perícia médica do INSS, concedendo um benefício acidentário quando positiva ${ }^{2,6,7,9,10}$.

O nexo cível é de natureza quantitativa, visto que, além de positivo ou negativo, tem como base o Código Civil. Necessita, para seu estabelecimento, da presença da culpa e do dano e é dada uma sentença com fixação de um valor arbitrado pelo magistrado, o que, para sua definição, envolve a análise de outros fatores, como: a capacidade financeira do empregador; a definição de um valor justo e adequado para o reclamante e que não proporcione enriquecimento ilícito; e o caráter educativo da indenização $0^{6,11-13}$.

Neste ensaio defendemos que podem ocorrer divergências na análise de acidente de trabalho/ doença ocupacional, conforme seja visto no foco trabalhista, previdenciário ou cível. Embasamos nossas ponderações pela experiência no ensino no exercício e na pesquisa de temas referentes à saúde coletiva e ocupacional dos autores deste trabalho, particularmente do primeiro autor, como médico do trabalho.

Notamos que, no estabelecimento da causalidade do acidente de trabalho, as divergências ocorrem dependendo da perspectiva de qual dos três "atores sociais" o determina: se o SESMT, responsável pela saúde e segurança do trabalhador acidentado; se o INSS, responsável pela concessão de benefícios ao segurado; ou se o Judiciário, responsável por julgar as causas oriundas das relações de trabalho ${ }^{7}$.

Parte-se do pressuposto de que a análise e comparação entre os fragmentos espalhados pela legislação trabalhista que dão suporte ao estabelecimento do nexo causal no acidente do trabalho pelos três atores sociais, SESMT, INSS e Judiciário, facilitaria na identificação dos seus fatores determinantes e das semelhanças e contradições entre eles. Entendendo que as três atuações são dependentes da conclusão da positividade ou negatividade do nexo causal, pretende-se que este ensaio possa contribuir para minimizar 
discussões desnecessárias, geralmente geradoras de retrabalho para os já assoberbados três atores sociais, desonerando, dessa forma, o chamado Custo Brasil.

Ante o exposto, este estudo tem como objetivo identificar e sistematizar atos normativos legais para subsidiar a compreensão interpretativa do nexo causal entre o sinistro laboral e o trabalho, nos âmbitos trabalhista, previdenciário e cível.

A finalidade é facilitar a análise do nexo causal pelo SESMT no foco de caracterização "técnico-legal”, pelo INSS na decisão previdenciária de conceder o benefício "de natureza acidentária” e no proferimento da sentença da Justiça do Trabalho, de forma a garantir os direitos e deveres de todos os envolvidos.

\section{Métodos}

Este ensaio é de natureza crítico-reflexiva, com base em levantamento e análise da legislação trabalhista brasileira. Foi realizado um estudo comparativo entre os fragmentos dispersos na legislação trabalhista que dão suporte ao estabelecimento do nexo causal no acidente do trabalho pelos três atores sociais considerados: SESMT (nexo trabalhista), INSS (nexo previdenciário) e Judiciário (nexo cível). Buscou-se identificar fatores que determinam semelhanças e contradições entre eles.

\section{A pluralidade do nexo causal em acidente de trabalho/doença ocupacional}

Os nexos trabalhista, previdenciário e cível têm em comum a Lei 8.213/19912 como base para o seu estabelecimento. No entanto, embora existam fatores comuns a todos, cada um se torna único, por apresentar características exclusivas, razão pela qual podem às vezes ser coincidentes e, às vezes, contrários, gerando conflitos ${ }^{6,7,11-16}$. Com base nas particularidades de cada nexo é possível compreender as eventuais divergências entre eles.

O nexo trabalhista (SESMT) é o que mais se encontra próximo do acidente e do ambiente laboral, sendo o primeiro dos três nexos a ser estabelecido, resultando na emissão, ou não, da Comunicação de Acidente do Trabalho (CAT).

O nexo previdenciário (INSS) tem como referência a Instrução Normativa $31^{6}$ que determina a existência de três espécies de nexo técnico previdenciário: o nexo técnico profissional ou do trabalho ${ }^{14}$; o nexo técnico por doença equiparada a acidente de trabalho ou nexo técnico individual, ou nexo técnico epidemiológico previdenciário (NTEP); e o individual, sendo este realizado sem a visita ao local do acidente, avaliando o acidentado geralmente dias ou semanas após a ocorrência, resultando na concessão ou não do benefício acidentário.

Já o nexo cível se baseia no Código Civil ${ }^{11}$, também muitas vezes sendo realizado sem a visita ao local do acidente e com avaliação do acidentado geralmente semanas, meses ou, às vezes, anos após a ocorrência. As avaliações suportam a sentença do juiz, se procedente ou improcedente a ação, determinando ou não indenização $0^{6,7,13}$.

Com base na comparação entre os nexos trabalhista, previdenciário e cível, como já mencionado, busca-se neste ensaio apontar as semelhanças e evidenciar as diferenças entre eles, assim como estudar os fatores que determinam essas diferenças e que caracterizam cada um dos três nexos como entidade única e bem definida. Esses fatores que caracterizam os três nexos determinam as razões pelas quais podem às vezes ser coincidentes, concordantes, complementares ou mesmo destoarem frontalmente, visto que cada um é estabelecido por determinado ator social (SESMT, INSS ou Justiça do Trabalho) com uma respectiva legislação a ser seguida.

Assim, observa-se no Quadro 1 a legislação principal e complementar utilizada pelas instituições responsáveis para determinar cada um dos respectivos nexos causais entre sinistro laboral e trabalho. Como se pode notar, a Lei 8.213/1991 é uma referência ${ }^{2}$ comum às três instituições (SESMT, INSS e Justiça do Trabalho), portanto com tendência a gerar conclusões similares nos três nexos, nos focos trabalhista, previdenciário e cível. É, portanto, a legislação complementar utilizada por cada uma das instituições que pode gerar eventuais diferenças na análise, definição e conclusões desses nexos causais.

Quadro 1 Legislação utilizada na análise dos nexos causais de acidente de trabalho/doença ocupacional

\begin{tabular}{|l|l|c|l|}
\hline \multirow{2}{*}{$\begin{array}{l}\text { Instituição } \\
\text { responsável }\end{array}$} & \multicolumn{1}{|c|}{$\begin{array}{c}\text { Tipo de } \\
\text { nexo causal }\end{array}$} & \multicolumn{1}{|c|}{ básica } & \multicolumn{1}{|c|}{ complementar } \\
\cline { 3 - 4 } SESMT* & $\begin{array}{l}\text { Nexo } \\
\text { trabalhista }\end{array}$ & Lei 8.213/1991 & $\begin{array}{l}\text { NR (Normas } \\
\text { Regulamentadoras) }\end{array}$ \\
\hline INSS*** & $\begin{array}{l}\text { Nexo } \\
\text { previdenciário }\end{array}$ & Lei 8.213/1991 & $\begin{array}{l}\text { Instrução } \\
\text { Normativa 31 }\end{array}$ \\
\hline $\begin{array}{l}\text { Justiça do } \\
\text { Trabalho }\end{array}$ & Nexo cível & Lei 8.213/1991 & Código Civil \\
\hline
\end{tabular}

*Serviços Especializados em Engenharia de Segurança e em Medicina do Trabalho

粎 Instituto Nacional do Seguro Social

O referencial normativo e a análise de cada nexo causal são apresentados de forma sintética e sistematizada para cada nexo, nos enfoques trabalhista (Quadro 2), previdenciário (Quadro 3) e cível (Quadro 4). 
Quadro 2 Principais legislações e textos aplicados à análise dos tipos de nexo trabalhista em acidente de trabalho/doença ocupacional

\begin{tabular}{|c|c|c|c|c|c|c|}
\hline egislação & \multicolumn{6}{|c|}{ Textos relacionados } \\
\hline & \multicolumn{2}{|l|}{ Artigo 19} & \multicolumn{2}{|l|}{ Artigo 20} & \multicolumn{2}{|l|}{ Artigo 21} \\
\hline Lei 8.213/1991 & \multicolumn{2}{|c|}{$\begin{array}{l}\text { Definição } \\
\text { “Acidente do trabalho é o } \\
\text { que ocorre pelo exercício do } \\
\text { trabalho a serviço da empresa } \\
\text { ou pelo exercício do trabalho } \\
\text { dos segurados referidos no } \\
\text { inciso VII do art. } 11 \text { desta Lei, } \\
\text { provocando lesão corporal } \\
\text { ou perturbação funcional } \\
\text { que cause a morte ou a perda } \\
\text { ou redução, permanente ou } \\
\text { temporária, da capacidade para } \\
\text { o trabalho." }\end{array}$} & \multicolumn{2}{|c|}{$\begin{array}{l}\text { Equiparação* } \\
\text { - Doenças profissionais e do trabalho. } \\
\text { - Doenças fora da relação prevista que } \\
\text { resultaram das especiais condições em } \\
\text { que o trabalho é executado e com ele } \\
\text { se relaciona diretamente. } \\
\text { - Situações de exclusão de culpa: } \\
\text { sabotagem, terrorismo, ato de } \\
\text { imprudência, negligência ou imperícia, } \\
\text { ato de pessoa privada do uso da razão, } \\
\text { desabamento, inundação, incêndio e } \\
\text { outros casos fortuitos ou decorrentes } \\
\text { de força maior. } \\
\text { - Outras situações: doença não incluída } \\
\text { na relação prevista nos incisos I e II } \\
\text { deste artigo* }\end{array}$} & \multicolumn{2}{|c|}{$\begin{array}{l}\text { Equiparação* } \\
\text { - Acidentes em que o trabalho participou } \\
\text { como “concausa”. } \\
\text { - Agressão, terrorismo, ofensa física } \\
\text { intencional, ato de imprudência e de pessoa } \\
\text { privada de razão, decorrentes de casos } \\
\text { fortuitos ou de força maior. } \\
\text { - Doença decorrente de contaminação } \\
\text { ambiental. } \\
\text { - Ainda que fora do local de trabalho: } \\
\text { prestação espontânea de serviço, execução } \\
\text { de ordem, viagem a serviço da empresa, } \\
\text { trajeto, períodos de descanso etc. } \\
\text { - 21-A NETP [...] ocorrência de nexo técnico } \\
\text { epidemiológico entre o trabalho e o agravo } \\
\text { [...]. } \\
\text { Descarte** } \\
\text { - Lesão resultante de acidente de outra } \\
\text { origem que se associe/superponha às } \\
\text { consequências do anterior. }\end{array}$} \\
\hline $\begin{array}{l}\text { Decreto } \\
3.048 / 1999 \\
\end{array}$ & \multicolumn{6}{|c|}{$\begin{array}{l}\text { Anexo II: listas } A \text { e } B \\
\text { Lista relacionando as doenças aos seus respectivos riscos laborais, binômio denominado de patologia risco-símile. }\end{array}$} \\
\hline & NR 4 & NR 7 & & NR 15 & NR 17 & NR 32 \\
\hline $\begin{array}{l}\text { Normas } \\
\text { Regulamenta-doras }\end{array}$ & \begin{tabular}{l|l|} 
4.12-h & \\
Atribui ao & \\
SESMT a & \\
responsabilidade & \\
do registro da & \\
CAT.
\end{tabular} & $\begin{array}{l}\text { 7.4.8-a } \\
\text { Determina a } \\
\text { de CAT em s } \\
\text { disfunção d } \\
\text { sistema biol } \\
\text { dos exames } \\
\text { dos Quadro } \\
\text { aqueles con } \\
\text { SC) e II; Ane } \\
\text { II, através da } \\
\text { de desencac } \\
\text { agravament } \\
\text { auditiva. } \\
\end{array}$ & $\begin{array}{l}\text { ertura } \\
\text { ações de } \\
\text { gão ou } \\
\text { ico, através } \\
\text { nstantes } \\
\text { apenas } \\
\text { terpretação } \\
\text { I do Quadro } \\
\text { efinição } \\
\text { mento e } \\
\text { e perda }\end{array}$ & \begin{tabular}{|l} 
5.1.4) \\
es \\
sendo \\
volvem \\
es de \\
ido \\
uando \\
ase nas \\
ionadas \\
quando \\
ela \\
balho.
\end{tabular} & $\begin{array}{l}17.1 \text { e anexos } \\
\text { Define parâmetros } \\
\text { que permitam a } \\
\text { adaptação das } \\
\text { condições de trabalho } \\
\text { às características } \\
\text { psicofisiológicas dos } \\
\text { trabalhadores. }\end{array}$ & \begin{tabular}{|l|}
32.2 .3 .5 \\
Em toda ocorrência \\
de acidente \\
envolvendo riscos \\
biológicos, com ou \\
sem afastamento do \\
trabalhador, \\
deve ser emitida a \\
Comunicação de \\
Acidente de Trabalho \\
(CAT).
\end{tabular} \\
\hline CLT & \multicolumn{6}{|c|}{$\begin{array}{l}\text { Artigo 169: } \\
\text { Determina a obrigatoriedade da notificação das doenças profissionais e das produzidas em virtude de condições } \\
\text { especiais de trabalho, comprovadas ou objeto de suspeita. }\end{array}$} \\
\hline CFM 1.488/1998 & \multicolumn{6}{|c|}{$\begin{array}{l}\text { Artigo } 2^{\circ} \text { : } \\
\text { Para o estabelecimento do nexo causal entre os transtornos de saúde e as atividades do trabalhador, além do exame } \\
\text { clínico (físico e mental) e dos exames complementares, quando necessários, deve o médico considerar: } \\
\text { I- a história clínica e ocupacional, decisiva em qualquer diagnóstico e/ou investigação de nexo causal; } \\
\text { II - o estudo do local de trabalho; } \\
\text { III - o estudo da organização do trabalho; } \\
\text { IV - os dados epidemiológicos; } \\
\text { V - a literatura atualizada; } \\
\text { VI - a ocorrência de quadro clínico ou subclínico em trabalhador exposto a condições agressivas; } \\
\text { VII - a identificação de riscos físicos, químicos, biológicos, mecânicos, estressantes e outros; } \\
\text { VIII - o depoimento e a experiência dos trabalhadores; } \\
\text { IX - os conhecimentos e as práticas de outras disciplinas e de seus profissionais, sejam ou não da área da saúde. }\end{array}$} \\
\hline Outras legisl & \multicolumn{6}{|c|}{$\begin{array}{l}\text { Outras referências como o uso da ACGIH pela ausência de limites de exposição à vibração na legislação brasileira: NR } \\
\text { 9.3.5.1, letra c: } \\
\text { "Quando os resultados das avaliações quantitativas da exposição dos trabalhadores excederem os valores dos limites } \\
\text { previstos na NR-15 ou, na ausência destes os valores limites de exposição ocupacional adotados pela ACGIH - American } \\
\text { Conference of Governmental Industrial Hygienists, ou aqueles que venham a ser estabelecidos em negociação coletiva de } \\
\text { trabalho, desde que mais rigorosos do que os critérios técnico-legais estabelecidos". }\end{array}$} \\
\hline
\end{tabular}

* São equiparadas ao acidente do trabalho;

**Não são consideradas como doença do trabalho 
Quadro 3 Principais legislações e textos aplicados à análise dos tipos de nexo previdenciário em Acidente de Trabalho/Doença Ocupacional

\begin{tabular}{|c|c|c|}
\hline Legislação & \multicolumn{2}{|l|}{ Textos relacionados } \\
\hline & Artigo 21-A & $\S 1^{\circ}$ \\
\hline Lei 8.213/1991 & $\begin{array}{l}\text { A perícia médica do INSS considerará caracterizada a natureza acidentária da } \\
\text { incapacidade quando constatar ocorrência de nexo técnico epidemiológico } \\
\text { entre o trabalho e o agravo, decorrente da relação entre a atividade da empresa } \\
\text { e a entidade mórbida motivadora da incapacidade elencada na Classificação } \\
\text { Internacional de Doenças (CID), em conformidade com o que dispuser o } \\
\text { regulamento. (Incluído pela Lei no }{ }^{\circ} 11.430 \text {, de } 28 \text { de dezembro de } 2006 \text { ) }\end{array}$ & $\begin{array}{l}\text { A perícia médica do INSS deixará } \\
\text { de aplicar o disposto neste } \\
\text { artigo quando demonstrada } \\
\text { a inexistência do nexo de que } \\
\text { trata o caput deste artigo. } \\
\text { (Incluído pela Lei } 11.430 / 2006 \text { ). }\end{array}$ \\
\hline \multirow{2}{*}{$\begin{array}{l}\text { Decreto } \\
3.048 / 1999\end{array}$} & \multicolumn{2}{|l|}{ Anexo II: listas $A$ e B e C } \\
\hline & \multicolumn{2}{|c|}{ Listas relacionando as doenças aos seus respectivos riscos laborais e tipos de atividades econômicas. } \\
\hline $\begin{array}{l}\text { Decreto } \\
6.042 / 2007\end{array}$ & \multicolumn{2}{|c|}{$\begin{array}{l}\text { NTEP (Nexo Técnico Epidemiológico de Prevenção) a partir do cruzamento das informaç̃ões de código da CID-10 } \\
\text { e de código da Classificação Nacional de Atividade Econômica (CNAE) aponta a existência de uma relação entre a } \\
\text { lesão ou agravo e a atividade desenvolvida pelo trabalhador. }\end{array}$} \\
\hline & \multicolumn{2}{|l|}{ Art. $3^{\circ}$ Nexo técnico previdenciário, três espécies: } \\
\hline $\begin{array}{l}\text { Instrução } \\
\text { Normativa } 31\end{array}$ & \multicolumn{2}{|c|}{$\begin{array}{l}\text { I- Nexo técnico profissional ou do trabalho, fundamentado nas associações entre patologias e exposições constantes } \\
\text { das listas A e B do Anexo II do Decreto 3.048/1999; } \\
\text { II - Nexo técnico individual, por doença equiparada a acidente de trabalho, decorrente de acidentes de trabalho } \\
\text { típicos ou de trajeto, bem como de condições especiais em que o trabalho é realizado e com ele relacionado } \\
\text { diretamente, nos termos do } 2^{\circ} \text { do art. } 20 \text { da Lei } 8.213 / 1991 ; \\
\text { III - NTEP, nexo técnico epidemiológico previdenciário, aplicável quando houver significância estatística da } \\
\text { associação entre o código da CID e o da CNAE, na parte inserida pelo Decreto } 6.042 / 2007 \text {, na lista B do Anexo II do } \\
\text { Decreto 3.048/1999. }\end{array}$} \\
\hline $\begin{array}{l}\text { Outras } \\
\text { legislações }\end{array}$ & \multicolumn{2}{|l|}{ Ordens de serviço, portarias, instruções normativas etc. } \\
\hline
\end{tabular}

Quadro 4 Principais legislações e textos aplicados à análise dos tipos de nexo cível em acidente de trabalho/ doença ocupacional

\begin{tabular}{|c|c|c|c|c|c|c|c|}
\hline \multirow[t]{2}{*}{ Legislação } & \multicolumn{7}{|c|}{ Textos relacionados } \\
\hline & Artigo 186 & Artigo 187 & Artigo 188 & Artigo 927 & Artigo 932 & Artigo 949 & Artigo 950 \\
\hline $\begin{array}{l}\text { Código } \\
\text { Civil }\end{array}$ & $\begin{array}{l}\text { Aquele que, } \\
\text { por ação } \\
\text { ou omissão } \\
\text { voluntária, } \\
\text { negligência } \\
\text { ou } \\
\text { imprudência, } \\
\text { violar direito } \\
\text { e causar dano } \\
\text { a outrem, } \\
\text { ainda que } \\
\text { exclusiva e } \\
\text { moralmente, } \\
\text { comete ato } \\
\text { ilícito. }\end{array}$ & $\begin{array}{l}\text { Também } \\
\text { comete ato } \\
\text { ilícito o titular } \\
\text { de um direito } \\
\text { que, ao exercê- } \\
\text { lo, excede } \\
\text { manifestamente } \\
\text { os limites } \\
\text { impostos } \\
\text { pelo seu fim } \\
\text { econômico ou } \\
\text { social, pela boa- } \\
\text { fé ou pelos bons } \\
\text { costumes. }\end{array}$ & $\begin{array}{l}\text { Não constituem } \\
\text { atos ilícitos: } \\
\text { I-os praticados } \\
\text { em legítima } \\
\text { defesa ou } \\
\text { no exercício } \\
\text { regular de } \\
\text { um direito } \\
\text { reconhecido; } \\
\text { II - a deterioração } \\
\text { ou destruição } \\
\text { da coisa alheia, } \\
\text { ou a lesão a } \\
\text { pessoa, a fim } \\
\text { de remover } \\
\text { perigo } \\
\text { iminente. }\end{array}$ & $\begin{array}{l}\text { Aquele } \\
\text { que, por } \\
\text { ato ilícito } \\
\text { (arts. } 186 \\
\text { e 187), } \\
\text { causar } \\
\text { dano a } \\
\text { outrem, } \\
\text { fica } \\
\text { obrigado a } \\
\text { repará-lo. }\end{array}$ & $\begin{array}{l}\text { Também são } \\
\text { responsáveis pela } \\
\text { reparação civil: } \\
\text { I- pais, pelos } \\
\quad \text { filhos menores } \\
\quad \text { sob sua } \\
\text { autoridade; } \\
\text { II - tutor e } \\
\text { curador, } \\
\text { pelos pupilos } \\
\text { e curatelados; } \\
\text { III - empregador } \\
\text { ou } \\
\text { comitente, } \\
\text { por seus } \\
\text { empregados/ } \\
\text { serviçais. }\end{array}$ & $\begin{array}{l}\text { No caso de } \\
\text { lesão ou outra } \\
\text { ofensa à saúde, } \\
\text { o ofensor } \\
\text { indenizará o } \\
\text { ofendido das } \\
\text { despesas do } \\
\text { tratamento } \\
\text { e dos lucros } \\
\text { cessantes } \\
\text { até o fim da } \\
\text { convalescença, } \\
\text { além de algum } \\
\text { outro prejuízo } \\
\text { que o ofendido } \\
\text { prove haver } \\
\text { sofrido. }\end{array}$ & \begin{tabular}{|l} 
Se o ofendido \\
não puder \\
exercer o \\
seu ofício/, a \\
indenização \\
incluirá pensão \\
correspondente \\
à importância \\
do trabalho \\
para que se \\
inabilitou, além \\
das despesas \\
do tratamento \\
até o fim da \\
convalescença.
\end{tabular} \\
\hline $\begin{array}{l}\text { Outras } \\
\text { legislações }\end{array}$ & \multicolumn{7}{|c|}{ Complementares. } \\
\hline
\end{tabular}

O SESMT (Quadro 2) julga com base nas $\mathrm{NRs}^{8}$, sendo a sua própria existência institucional devido, aliás, à obrigatoriedade de uma dessas normas, a Norma Regulamentadora 04 - Serviços Especializados em Engenharia de Segurança e em Medicina do Trabalho (SESMT), que determina a sua responsabilidade pela saúde, segurança e integridade do trabalhador nas corporações, além da geração da documentação trabalhista pertinente, inclusive da emissão da CAT. Portanto, o SESMT avalia o acidente do trabalho com base nas características do ambiente laboral, já que conhece previamente os 
riscos ambientais. A conclusão da sua análise é o registro, ou não, da CAT, ou seja, se conclui pelo nexo causal positivo, registra a CAT, ou se conclui pelo nexo negativo, a CAT não é registrada ${ }^{10}$.

O julgamento do INSS (Quadro 3) é subsidiado pela Instrução Normativa $31^{8}$, avaliando o acidentado com base em três parâmetros nela estabelecidos, porém sem visitar o ambiente laboral. Os parâmetros são:

I - Nexo técnico profissional ou do trabalho, fundamentado nas associações entre patologias e exposições constantes das listas A e B do Anexo II do Decreto ${ }^{\circ}{ }^{3.048}$, de 6 de maio de 19999;

II - Nexo técnico individual, por doença equiparada a acidente de trabalho, decorrente de acidentes de trabalho típicos ou de trajeto, bem como de condições especiais em que o trabalho é realizado e com ele relacionado diretamente, nos termos do $\S 2^{\circ}$ do art. 20 da Lei 8.213/1991²;

III - Nexo técnico epidemiológico previdenciário (NTEP), aplicável quando houver significância estatística da associação entre o código da Classificação Internacional de Doenças (CID) e o da Classificação Nacional de Atividades Econômicas (CNAE), na parte inserida pelo Decreto $\mathrm{n}^{\mathrm{o}}$ 6.042, de 12 de fevereiro de
$2007^{15}$, na lista B do Anexo II do Decreto $3.048 / 1999^{9}$. A sua conclusão final é a concessão do benefício de natureza acidentária ou não acidentária, ou seja, se conclui pelo nexo causal positivo, concede um benefício acidentário, ou se conclui pelo nexo negativo, concede um benefício não acidentário.

A Justiça do Trabalho (Quadro 4) é competente na apreciação e no julgamento das demandas de indenização por dano moral ou patrimonial originados da relação de trabalho ${ }^{16}$. Baseia sua análise no Código Civil ${ }^{11}$, conforme os artigos 186, 187, 188, 927, 932, 949 e 950, que estabelecem a obrigatoriedade em reparar danos ilícitos causados a outrem. A sua conclusão final é a sentença judicial procedente ou improcedente, ou seja, se conclui pelo nexo negativo, a sentença resultará em improcedente, ou, ao contrário, se conclui nexo causal positivo a sentença, resultará em procedente, arbitrando uma indenização de valor variado (quantum indenizatório).

No Quadro 5 são descritos e comentados a instituição responsável por realizar o julgamento do acidente de trabalho, o produto final do julgamento, a proximidade com o acidente, a natureza do julgamento, as influências para notificar ou não o acidente e o embasamento legal para cada tipo de nexo causal (trabalhista, previdenciário e cível), evidenciando a lógica e as conclusões deles.

Quadro 5 Particularidades de cada nexo causal (trabalhista, previdenciário e cível) segundo o fator avaliado, descrição e comentários

\begin{tabular}{|c|c|c|c|}
\hline Tipo de nexo & Fator avaliado & Descrição & Comentários \\
\hline Trabalhista & \multirow{3}{*}{$\begin{array}{l}\text { Instituição } \\
\text { responsável }\end{array}$} & SESMT & $\begin{array}{l}\text { - O acidente é investigado pelo SESMT, sendo ao final } \\
\text { concluído quanto à existência ou não existência do nexo } \\
\text { causal. Em caso positivo, é registrado como tal no INSS } \\
\text { pela emissão da CAT. }\end{array}$ \\
\hline Previdenciário & & INSS & $\begin{array}{l}\text { - A perícia médica do INSS homologa tal agravo como sendo } \\
\text { ou não do trabalho. }\end{array}$ \\
\hline Cível & & Justiça do Trabalho & $\begin{array}{l}\text { - Justiça do Trabalho, podendo ter como base os "olhos } \\
\text { técnicos" do perito. }\end{array}$ \\
\hline Trabalhista & \multirow{3}{*}{ Produto final } & CAT registrada & $\begin{array}{l}\text { - Registro da CAT no INSS para sua homologação pela } \\
\text { perícia médica do INSS. }\end{array}$ \\
\hline Previdenciário & & $\begin{array}{l}\text { CAT homologada (acidentário ou "não } \\
\text { acidentário") e concessão do benefício }\end{array}$ & $\begin{array}{l}\text { - Homologação do sinistro laboral e liberação do benefício } \\
\text { como acidentário ou não acidentário. }\end{array}$ \\
\hline Cível & & Sentença/quantum indenizatório & $\begin{array}{l}\text { - Sentença com eventual reparação do dano, com base em } \\
\text { fatores: pedagógico, capacidade econômica da empresa, } \\
\text { extensão do dano, dimensão da culpa etc. }\end{array}$ \\
\hline Trabalhista & \multirow{3}{*}{$\begin{array}{l}\text { Proximidade } \\
\text { com o } \\
\text { acidente }\end{array}$} & Relação direta & - Dos três nexos é o mais próximo do ambiente laboral. \\
\hline Previdenciário & & Alheio ao ambiente laboral & - Na prática, sem qualquer relação com o ambiente laboral. \\
\hline Cível & & Alheio ao ambiente laboral & $\begin{array}{l}\text { - Embora predominantemente não há visita ao local de } \\
\text { trabalho, alguns peritos que fogem a esta regra e avaliam } \\
\text { o posto de trabalho. }\end{array}$ \\
\hline
\end{tabular}

(Continua) 
Quadro 5 Continuação...

\begin{tabular}{|c|c|c|c|}
\hline Tipo de nexo & Fator avaliado & Descrição & Comentários \\
\hline Trabalhista & \multirow{3}{*}{ Natureza } & Qualitativo & $\begin{array}{l}\text { - A conclusão final é o registro ou não registro da CAT, ou } \\
\text { seja, é ou não causa do trabalho. }\end{array}$ \\
\hline Previdenciário & & Qualitativo & $\begin{array}{l}\text { - Qualifica o sinistro laboral: acidentário ou não acidentário. } \\
\text { Portanto, pode concordar ou não com a conclusão do } \\
\text { SESMT. Obs.: A autoridade para tal conclusão é do INSS. }\end{array}$ \\
\hline Cível & & Quantitativo & $\begin{array}{l}\text { - A reparação do dano é determinada pelo estabelecimento } \\
\text { do “quantum indenizatório" pelo magistrado no } \\
\text { proferimento da sentença. É importante que o perito, } \\
\text { além de definir o nexo acidentário (nexo positivo) ou não } \\
\text { acidentário (nexo negativo), enriqueça o seu laudo com } \\
\text { informações acerca do risco (ambiência laboral) e do dano. }\end{array}$ \\
\hline Trabalhista & \multirow{3}{*}{$\begin{array}{l}\text { Influências } \\
\text { externas }\end{array}$} & $\begin{array}{l}\text { Subnotificação*" } \\
\text { "Supernotificação"**** }\end{array}$ & $\begin{array}{l}\text { - Corporativa: empresa pode “coibir” a notificação devido a: } \\
\text { desconhecimento técnico, omissão intencional, outros. } \\
\text { - Empregado: pressões pelo trabalhador (segurado), } \\
\text { familiares, sindicatos etc. } \\
\text { - Órgãos governamentais: MTE, MPT, Judiciário. }\end{array}$ \\
\hline Previdenciário & & $\begin{array}{l}\text { Subnotificação" } \\
\text { "Supernotificação"*** }\end{array}$ & $\begin{array}{l}\text { - Corporativa: empresa pode contestar o nexo do INSS devido } \\
\text { a: desconhecimento técnico, omissão intencional, outros. } \\
\text { - Empregado: pressões pelo trabalhador (segurado), } \\
\text { familiares, sindicatos etc. } \\
\text { - Órgãos governamentais: MTE, MPT, Judiciário. }\end{array}$ \\
\hline Cível & & 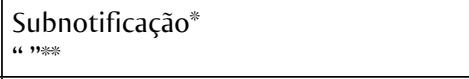 & $\begin{array}{l}\text { - Empregador: assistente técnico, prepostos etc. } \\
\text { - Perito, INSS, MPT, MTE. }\end{array}$ \\
\hline Trabalhista & \multirow{3}{*}{$\begin{array}{l}\text { Embasamento } \\
\text { legal/geral }\end{array}$} & $\begin{array}{l}\text { - NR 4, NR 7, NR 15, NR 17, NR 32; } \\
\text { - Lei 8.213/1991; } \\
\text { - Decreto 3.048/1999 (anexos A e B); } \\
\text { - CLT; } \\
\text { - Resolução CFM 1.488/2008; } \\
\text { - Outras. }\end{array}$ & $\begin{array}{l}\text { - Conhecimento técnico-legal, tanto do agravo (“lesão, } \\
\text { doença, transtorno de saúde, distúrbio, disfunção ou } \\
\text { síndrome de evolução aguda, subaguda ou crônica, } \\
\text { de natureza clínica ou subclínica, inclusive morte, } \\
\text { independentemente do tempo de latência”) quanto da } \\
\text { legislação trabalhista brasileira vigente e ouvir o acidentado, } \\
\text { testemunhas etc. Obs.: O conhecimento do ambiente } \\
\text { laboral pelo SESMT é imprescindível. }\end{array}$ \\
\hline Previdenciário & & $\begin{array}{l}\text { - Lei 8.213/1991, artigo } 21 \text { e } \S 1^{\circ} \text {; } \\
\text { - Decreto 3.048/1999 (Listas A, B e C); } \\
\text { - Decreto 6.042/2007; } \\
\text { - Instruções Normativas (IN 31: } \\
\text { nexos profissional, individual e do } \\
\text { trabalho); } \\
\text { - Outras. }\end{array}$ & $\begin{array}{l}\text { - Com base na legislação e nas informações do segurado, } \\
\text { familiares ou colegas do segurado (em caso de morte do } \\
\text { segurado). } \\
\text { Obs.: Efetivamente não há visita ao posto de trabalho. }\end{array}$ \\
\hline Cível & & $\begin{array}{l}\text { - NR 4, NR 7, NR 15, NR 17, NR 32; } \\
\text { - Lei 8.213/1991; } \\
\text { - Decreto 3.048/1999 (anexos A e B); } \\
\text { - CLT; } \\
\text { - Resolução CFM 1.488/1998; } \\
\text { - Outras. }\end{array}$ & $\begin{array}{l}\text { - São utilizadas as mesmas legislações do nexo trabalhista } \\
\text { e algumas considerações sobre a legislação previdenciária } \\
\text { pelo perito, porém, extrapolando além da simples e } \\
\text { "binária" positividade ou negatividade do nexo causal, } \\
\text { objetivando enriquecer o laudo com informações que } \\
\text { podem auxiliar na posterior sentença do magistrado, } \\
\text { quanto à conclusão final do nexo causal, e na presença } \\
\text { e magnitude da "culpa" para orientar o quantum } \\
\text { indenizatório. }\end{array}$ \\
\hline
\end{tabular}

* Influências para não notificar o acidente. *** Influências para notificar o acidente.

\section{Conclusão}

Embora se fale indistintamente do nexo causal no acidente do trabalho como se fosse o único, na verdade, "nexo causal" é um homônimo que remete a três conclusões que podem ser ora coincidentes, ora complementares, porém, às vezes, até contrárias. Isso ocorre, por um lado, pela existência de leis comuns a todos, por outro, por haver leis específicas para a atuação de cada instituição, levando cada uma a agir seguindo a sua própria "cartilha".

Nesse sentido, observa-se a necessidade da realização de um trabalho conjunto e conciso, que possibilite a interação entre tais instituições, de modo a 
evitar julgamentos incoerentes e contrários uns aos outros. Para tal, a utilização de um sistema de informação interligado poderia colaborar para o registro e o julgamento das informações relacionadas ao/à acidente de trabalho/doença ocupacional.

A sistematização das informações relacionadas ao nexo causal contidas neste ensaio pretendeu trazer maior subsídio à análise e discussão do tema, diminuindo a grande dificuldade de compreensão e, consequentemente, de prejuízos, em especial para o acidentado, mas também para os demais "atores sociais" envolvidos, como o empregador, o INSS, o SUS (Sistema Único de Saúde), o MTb (Ministério do Trabalho), o MPT (Ministério Público do Trabalho) e o Judiciário.

\section{Contribuição dos autores}

Todos os autores contribuíram substancialmente no delineamento, no levantamento de dados, na sua análise, interpretação e na elaboração e aprovação da versão final do manuscrito.

\section{Referências}

1. Bordoni PHC, Bordoni LS, Silva JM, Drumond EF. Utilização do método de captura-recaptura de casos para a melhoria do registro dos acidentes de trabalho fatais em Belo Horizonte, Minas Gerais, 2011. Epidemiol Serv Saúde. 2016;25(1):85-94.

2. Brasil. Ministério da Previdência Social. Lei 8.213, de 24 de julho de 1991. Dispõe sobre os planos de benefícios da Previdência Social e dá outras providências. Diário Oficial da União. 25 jul 1991. Seção 1:14809.

3. Brasil. Presidência da República. Lei Complementar 150, de $1^{\circ}$ de junho de 2015. Dispõe sobre o contrato de trabalho doméstico; altera as Leis n. 8.212, de 24 de julho de 1991, n. 8.213, de 24 de julho de 1991, e n. 11.196, de 21 de novembro de 2005; revoga o inciso I do art. 3 da Lei n. 8.009, de 29 de março de 1990, o art. 36 da Lei n. 8.213, de 24 de julho de 1991, a Lei n. 5.859, de 11 de dezembro de 1972, e o inciso VII do art. 12 da Lei n. 9.250, de 26 de dezembro 1995; e dá outras providências. Diário Oficial da União. 2 jun 2015. Seção 1:1-4.

4. Dantas RAA. Perícia médica: avaliando danos e constatando incapacidade. São Paulo: LTR; 2010. p. 33.

5. Brandimiller PA. Perícia judicial em acidentes e doenças do trabalho. São Paulo: SENAC; 1996. p. 161.

6. Cabral LAA. Abre a CAT?: Nexo causal no acidente do trabalho e doença ocupacional. 4. ed. São Paulo: LTE; 2014.

7. Cabral LAA, Soler ZASG, Lopes JC. "Acidente de dupla espécie": uma terceira espécie de acidente do trabalho e sua importância para a vigilância em saúde do trabalhador. Ciênc Saúde Coletiva. 2014;19(12):4699-708.

8. Brasil. Ministério do Trabalho. Portaria $n^{\circ} 3.214$, de 8 de junho de 1978. Aprova as Normas Regulamentadoras - NR - do Capítulo V, Título II, da Consolidação das Leis do Trabalho, relativas a
Segurança e Medicina do Trabalho. Diário Oficial da União. 6 jul 1978. Suplemento.

9. Brasil. Presidência da República. Decreto 3.048, de 6 de maio de 1999. Aprova o Regulamento da Previdência Social, e dá outras providências. Diário Oficial da União. 18 jun 1999. Seção 1:32.

10. Brasil. Instrução Normativa INSS/PRES n ${ }^{\circ}$ 31, de 10 de setembro de 2008. Dispõe sobre procedimentos e rotinas referentes ao Nexo Técnico Previdenciário, e dá outras providências. Diário Oficial da União. 11 set 2008. Seção 1:58.

11. Brandão C. Acidente do trabalho e responsabilidade civil do empregador. 2. ed. São Paulo: LTR; 2006.

12. Oliveira SG. Proteção jurídica à saúde do trabalhador. 6. ed. São Paulo: LTR; 2011. p. 324.

13. Araújo Junior FM. Doença ocupacional e acidente do trabalho: análise multidisciplinar. São Paulo: LTR; 2009.

14. Matos AB, Hostensky EL. Fator acidentário de Prevenção (FAP) e nexo técnico Epidemiológico Previdenciário (NTEP): indicadores para uma intervenção psicossocial. Psicol Soc. 2016:28(1):145-50.

15. Brasil. Presidência da República. Decreto 6.042, de 12 de fevereiro de 2007. Altera o Regulamento da Previdência Social, aprovado pelo Decreto n. 3.048, de 6 de maio de 1999, disciplina a aplicação, acompanhamento e avaliação do Fator Acidentário de Prevenção - FAP e do Nexo Técnico Epidemiológico, e dá outras providências. Diário Oficial da União. 13 fev 2007. Seção 1:2.

16. Brasil. Emenda Constitucional $n^{\circ} 45$, de 30 de dezembro de 2004. Altera dispositivos dos arts. $5^{\circ}$, $36,52,92,93,95,98,99,102,103,104,105,107$, 109, 111, 112, 114, 115, 125, 126, 127, 128, 129, 134 e 168 da Constituição Federal, e acrescenta os arts. 103-A, 103B, 111-A e 130-A, e dá outras providências. Diário Oficial da União. 31 dez 2004. Seção 1:9. 